\title{
Pteridines and mono-amines: relevance to neurological damage
}

\author{
I. Smith, D.W. Howells and K. Hyland \\ Institute of Child Health (University of London), 30 Guilford Street, London WC1N 2NR, UK.
}

\begin{abstract}
Summary: Patients with phenylalanine hydroxylase deficiency show increased concentrations of biopterins and neopterins, and reduced concentrations of serotonin and catecholamines, when phenylalanine concentrations are raised. The pterin rise reflects increased synthesis of dihydroneopterin and tetrahydrobiopterin, and the amine fall a reduction in amine synthesis due to inhibition by phenylalanine of tyrosine and tryptophan transport into neurones. The pterin and amine changes appear to be independent of each other and are present in the central nervous system as well as the periphery; they disappear when phenylalanine concentrations are reduced to normal. Patients with arginase deficiency show a similar amine disturbance but have normal pterin levels. The amine changes probably contribute neurological symptoms but pterin disturbance is not known to affect brain function.

Patients with defective biopterin metabolism exhibit severely impaired amine synthesis due to tetrahydrobiopterin deficiency. Pterin concentrations vary with the site of the defect. Symptoms include profound hypokinesis and other features of basal ganglia disease. Neither symptoms nor amine changes are relieved by controlling phenylalanine concentrations. Patients with dihydropteridine reductase (DHPR) deficiency accumulate dihydrobiopterins and develop secondary folate deficiency which resembles that occurring in patients with defective 5,10-methylene tetrahydrofolate reductase activity. The latter disorder is also associated with Parkinsonism and defective amine and pterin turnover in the central nervous system, and a demyelinating illness occurs in both disorders. In DHPR deficiency cerebral calcification may develop in a similar distribution to that seen in congenital folate malabsorption and methotrexate toxicity. Symptoms are ameliorated by therapy with 5-formyltetrahydrofolate but exacerbated by folic acid.
\end{abstract}

\section{Introduction}

Alterations in amine metabolism are a factor in the pathogenesis of many diseases. Two of the commonest neurological disorders, Parkinson's disease and Alzheimer's disease, are associated with a central deficiency of catecholamines and serotonin, many drugs in common use interfere with amine metabolism and it has been proposed that the major psychoses are due to defective control of amine turnover, although the mechanisms of amine disturbance are ill understood.

In the clinical literature relatively little attention has been paid to the possible role of the rate controlling reactions of amine synthesis although there are several clearly defined examples of disorders which lead to amine deficiency due to alterations at this site in amine metabolism. Patients with phenylketonuria for example have long been known to exhibit amine abnormalities due to this cause. The two hydroxylation reactions which control the rate of catecholamine and serotonin synthesis require the same cofactor, tetrahydrobiopterin $\left(\mathrm{BH}_{4}\right)$ which is a pteridine compound structurally related to folates, and 10 years ago the

Correspondence: I. Smith, B.Sc., F.R.C.P., D.C.H. first patients with the defective $\mathrm{BH}_{4}$ metabolism were described (Smith, 1985). They exhibit profound amine deficiency and neurological symptoms consist initially of poor head control, floppiness, feeding problems, excessive drooling and sweating, blank facies, general immobility and lethargy usually appearing within a few weeks or months of birth. Later symptoms include profound truncal hypotonia contrasting with cogwheel or lead-pipe rigidity of the limbs, choreiform movements, oculogyric crises, infantile spasms, swallowing difficulty, disturbance of temperature control and respiratory problems, progressive developmental regression and intractable epilepsy. Death in early childhood is common among patients recorded in the literature. Control of hyperphenylalaninaemia (HP) by means of a low phenylalanine diet fails to correct the amine disturbance or prevent the progression of clinical symptoms.

It is too soon to say how well patients with $\mathrm{BH}_{4}$ deficiency will progress on long-term amine precursor therapy. Bearing in mind the effects of HP on brain protein and lipid metabolism and that L-dopa and 5hydroxytryptophan enter the brain via the same 
transport process as the other neutral amino acids and will therefore compete for entry into neurones, one cannot be certain that such therapy will have long term success. The cause of the deterioration seen in patients with Parkinson's disease after a few years on L-dopa therapy is not understood but may be due, at least in part, to therapy.

These disorders have provided important insights into the mechanisms and consequences of altered amine metabolism in vivo. In addition, unexpected links between folate, biopterin and amine metabolism have emerged which throw new light upon an old problem, subacute combined degeneration of the cord. These recent discoveries are likely to add to understanding of the mechanisms of neurological disease, but, as yet, the findings are little known beyond the narrow field of metabolic disease and details of the biochemical background are not readily accessible to the general reader.

The aim here is to bring together the relevant biochemical information and illustrate this with some recent findings in children with phenylalanine hydroxylase deficiency, arginase deficiency, defects of biopterin metabolism and defects of folate metabolism. The relationships between neurological and biochemical abnormalities are discussed.

\section{Pteridines}

Natural pteridines contain a 2-amino,4-oxopteridine (or 'pterin') ring (Pfleiderer, 1982). Folic acid and biopterin contain a fully oxidized pterin ring (five double bonds) but in vivo the number and disposition of double bonds and protons are in the dihydro- or tetrahydro- form (Figure 1), enabling pteridines to act as proton donors and acceptors. Various substituent groups may be attached at position 6 , biopterins having a dihydroxypropyl, and folates a methylene/ $p$ - aminobenzoate/glutamate group. Folates may carry additional methyl $\left(\mathrm{CH}_{3}\right)$, formyl (CHO), or formimino $(\mathrm{CHNH})$ groups at $\mathrm{N} 5, \mathrm{CHO}$ at $\mathrm{N} 10$ or methenyl $(\mathrm{CH})$ or methylene $\left(\mathrm{CH}_{2}\right)$ groups linking $\mathrm{N} 5$ and $\mathrm{N} 10$, reflecting the role of folate in 1-carbon transfer. amethopterin (methotrexate) is a synthetic pteridine which differs from folic acid in having an amino- group instead of an oxo- group at position 4 and a methyl group at position 10 . The molybdenum cofactor is also a pteridine (Coughlan, 1983) but will not be discussed here.

\section{Metabolism of biopterins}

\section{5,6,7,8-tetrahydrobiopterin $\left(\mathrm{BH}_{4}\right)$}

BH4 is the proton donor in the hydroxylation of phenylalanine to tyrosine, tyrosine to L-dopa and tryptophan to 5-hydroxytryptophan (Figure 2) (Kaufman, 1981). Phenylalanine hydroxylase, which is confined to liver, controls the rate of phenylalanine catabolism and deficiency of this enzyme, or of its cofactor $\mathrm{BH}_{4}$, leads to hyperphenylalaninaemia (Kaufman, 1976; Smith, 1985). Tyrosine and tryptophan hydroxylases control the rate of dopamine and serotonin synthesis respectively (Kaufman, 1981). 5Hydroxytryptophan is also the precursor of melatonirg in the pineal. $\mathrm{BH}_{4}$, or a similar tetrahydroptering appears to be required for breakdown of the ethes bond of plasmalogens (Tietz et al., 1964) and the possibility of $\mathrm{BH}_{4}$ being involved in other oxidation/ reduction reactions cannot be excluded.

\section{Synthesis and turnover of $\mathrm{BH}_{4}$}

$\mathrm{BH}_{4}$ is synthesized (Figure 2) in liver and in amine producing cells from guanosine triphosphate (GTP) which is converted to 7,8-dihydroneopterin triphos-

1<smiles>Nc1nc2c(c(=O)[nH]1)N[C@H](CN=[NH+]c1ccc(C(=O)NC(CCC(=O)O)C(=O)O)cc1)CN2</smiles>

2<smiles></smiles>

Figure 1 (1) 5,6,7,8-tetrahydrofolate (THF); (2) 5,6,7,8-tetrahydrobiopterin $\left(\mathrm{BH}_{4}\right)$. 


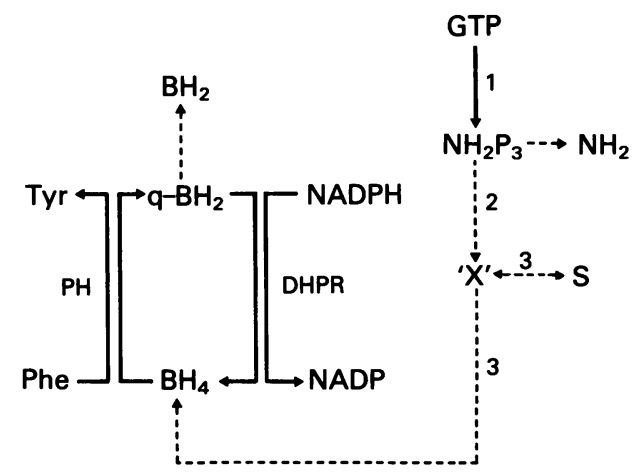

Figure 2 Requirement for tetrahydrobiopterin $\left(\mathrm{BH}_{4}\right)$ in the conversion of phenylalanine (Phe) to tyrosine (Tyr) and synthesis of $\mathrm{BH}_{4}$ from guanosine triphosphate (GTP). The same mechanisms of $\mathrm{BH}_{4}$ turnover are required in the hydroxylation of tyrosine to L-dopa and tryptophan to 5-hydroxytryptophan. $\mathrm{PH}=$ phenylalanine hydroxylase, DHPR = dihydropteridine reductase, 1 = GTP cyclohydrolase, 2 = 'dephosphorylating enzyme', 3 = sepiapterin reductase, $\mathrm{NH}_{2}=$ dihydroneopterin, $\mathrm{NH}_{2} \mathrm{P}_{3}=$ neopterin triphosphate, $\mathrm{S}=$ sepiapterins, $\mathrm{BH}_{2}=7,8$, dihydrobiopterin, $\mathrm{q}-\mathrm{BH}_{2}=$ quinonoid-dihydrobiopterin.

phate $\left(\mathrm{NH}_{2} \mathrm{P}_{3}\right)$ by GTP cyclohydrolase. $\mathrm{NH}_{2} \mathrm{P}_{3}$ is dephosphorylated and reduced to form $\mathrm{BH}_{4}$ in a series of reactions requiring at least two enzymes ('phosphate eliminating enzyme' and sepiapterin reductase) and several tetrahydroketopterin intermediates (Curtius et al., 1985; Kaufman, 1985). Organisms synthesizing folates do so from GTP via $\mathrm{NH}_{2} \mathrm{P}_{3}$.

$\mathrm{BH}_{4}$ is oxidized during the hydroxylation of aromatic amino acids to quinonoid-dihydrobiopterin $\left(\mathrm{q}-\mathrm{BH}_{2}\right)$ which is then reduced back to $\mathrm{BH}_{4}$ by dihydropteridine reductase (DHPR) (Figure 2) (Kaufman, 1971). This re-cycling of biopterins is essential for maintenance of a normal rate of hydroxylation in vivo. $\mathrm{q}-\mathrm{BH}_{2}$ readily rearranges to 7,8-dihydrobiopterin $\left(\mathrm{BH}_{2}\right)$ which cannot then be reduced to $\mathrm{BH}_{4}$ by DHPR.

\section{7,8-dihydroneopterin $\left(\mathrm{NH}_{2}\right)$}

$\mathrm{NH}_{2}$ is present in human tissue fluids (but not those of the rat). It has been assumed that $\mathrm{NH}_{2}$ is a bi-product of $\mathrm{BH}_{4}$ synthesis but with the possible exception of $\mathrm{NH}_{2}$ in patients with defective conversion of $\mathrm{NH}_{2} \mathrm{P}_{3}$ to $\mathrm{BH}_{4}$, it seems more likely that this pterin arises mainly in the reticulo-endothelial system. Macrophages, which do not synthesize biopterins, contain GTP cyclohydrolase and produce neopterins in response to activated T-cells. This is probably the origin of markedly elevated blood and urine neopterins in patients with viral infection, malignant disorders, graft versus host disease and gluten enteropathy (Huber et al., 1983).

\section{GTP cyclohydrolase}

This enzyme appears to control the rate of $\mathrm{BH}_{4}$ and $\mathrm{NH}_{2}$ synthesis. Incorporation of GTP into $\mathrm{BH}_{4}$ in the rat is stimulated by hyperphenylalaninaemia (Milstien \& Kaufman, 1983) which, in human subjects, leads to a rise in plasma and urine biopterins and neopterins (Leeming et al., 1976a; Dhont et al., 1981; Niederwieser et al., 1980). Even when phenylalanine concentrations are within the normal range, plasma concentrations of biopterins change in parallel with phenylalanine suggesting that the latter exerts physiological control over $\mathrm{BH}_{4}$ synthesis (Smith, 1985).

\section{Measurement of pteridines in biological fluids}

Reduced pteridines are readily oxidized and measurement of individual species presents many practical difficulties. Bio-assay of 'total folate' using Lactobacillus caseii and 'total biopterin' using Crithidia fasciculata provide sensitive measures of the combined activity of reduced and oxidized species. Combined with measurement of DHPR activity bioassay of biopterins in dried blood spots is used in the UK for routine testing for defective $\mathrm{BH}_{4}$ metabolism in infants with hyperphenylalaninaemia (Leeming $e t$

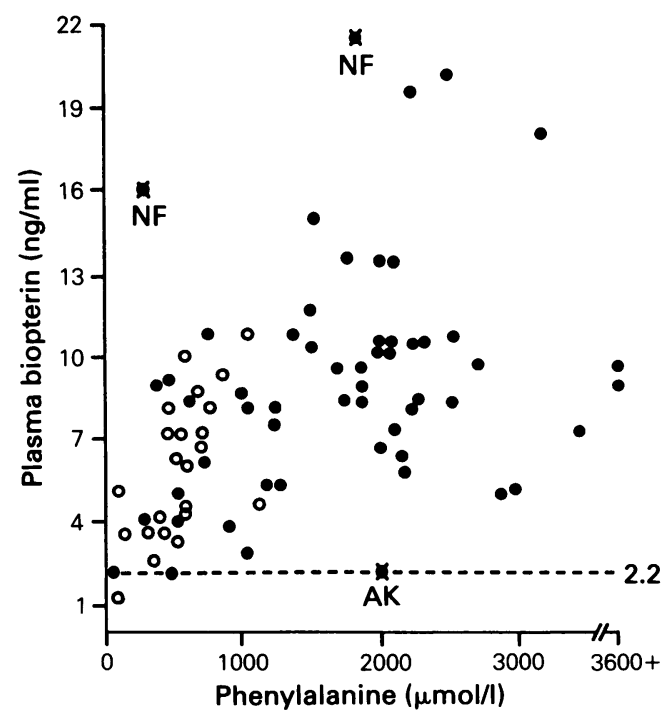

Figure 3 Relationship between plasma phenylalanine concentrations and plasma total biopterin activity in newborn infants with hyperphenylalaninaemia. Patient NF: DHPR deficiency. Patient AK: defective biopterin synthesis. (O) pre-diet; $(O)$ on diet. 
al. 1984). It is also useful for measuring the response of plasma biopterins to a phenylalanine load as a test of defective biopterin synthesis (Leeming et al., 1976; Rey et al., 1983). The assay provides no measure of neopterins and loss of $\mathrm{BH}_{4}$ occurs during the procedure.

Chemical techniques for measurement of total biopterins and neopterins using high performance liquid chromatography (HPLC) with pre-column oxidation and fluorimetric detection (Nixon et al., 1980) have been applied in the diagnosis of $\mathrm{BH}_{4}$ deficiency (Niederwieser et al., 1980; Niederwieser et al., 1985). The technique will allow for an approximate estimate of the proportions of $\mathrm{BH}_{4}$ in the original sample (Nixon et al., 1980). By using electrochemical and fluorimetric detectors in series, $\mathrm{BH}_{4}, \mathrm{BH}_{2}$ and biopterin can be measured directly (Hyland, 1985; Hyland $e t$ al., in press). Pre-column autoxidation is minimized by collection of specimens into tubes containing anti-oxidant (vitamin $\mathrm{C}$, dithioerythritol and an iron chelator), protection from light and freezing to $-70^{\circ}$ at the bedside.

\section{Pteridines in various forms of hyperphenylalaninaemia}

\section{Phenylalanine hydroxylase deficiency}

As might be expected from the effects of phenylalanine on GTP cyclohydrolase, patients show a rise in plasma total biopterin in the presence of hyperphenylalaninaemia (Figure 3). Concentrations of biopterins and neopterins are increased in urine (Niederwieser et al., 1980) and in blood (Dhondt et al., 1981) most biopterins being in the tetrahydro-form (Nixon et al., 1980; Dhondt et al., 1981). These pterin changes disappear when phenylalanine levels are controlled by means of a low phenylalanine diet. Administration of $\mathrm{BH}_{4}$ does not affect phenylalanine concentrations.
CSF biopterins and neopterins appear to be increased, reflecting peripheral pterins and again most of the biopterin activity is $\mathrm{BH}_{4}$ (Table $\left.\mathrm{I}\right)$. It is not known whether pterin changes have any effect on neurological status. Despite careful handling of specimens to prevent oxidation, significant amounts of $\mathrm{BH}_{2}$ and dihydroxanthopterin, which are probably derived from oxidation of pteridines in vitro, could be detected in CSF.

\section{Tetrahydrobiopterin deficiency}

$\mathrm{BH}_{4}$ deficiency may be due to deficiency of GTP cyclohydrolase, to defective conversion of $\mathrm{NH}_{2} \mathrm{P}_{3}$ to $\mathrm{BH}_{4}$ or to DHPR deficiency (Niederwieser et al., 1985) (Figure 2). Administration of $\mathrm{BH}_{4}$ to these patients lowers plasma phenylalanine and raises tyrosine concentrations, although in DHPR deficiency amino acid changes are small or, in a few patients, undetectable. Plasma total biopterin activity is low in patients with defective biopterin synthesis (Leeming et al., 1976b; Rey et al., 1977; Niederwieser et al., 1984) and the urine pterin pattern is characteristic of each defect. Patients with GTP cyclohydrolase deficiency have low concentrations of biopterins and neopterins and those with defective conversion of $\mathrm{NH}_{2} \mathrm{P}_{3}$ to $\mathrm{BH}_{4}$ have high concentrations of neopterins and low biopterins (Niederwieser et al., 1985). In DHPR deficiency plasma and urine biopterins are raised (Rey et al., 1977; Smith et al., 1985) whereas neopterins are normal (Dhondt et al., 1981; Niederwieser et al., 1980). Direct measurement of biopterins in the urine of two patients with DHPR deficiency has shown the main species to be $\mathrm{BH}_{2}$ (Hyland, 1985), not biopterin as suggested previously (Milstien et al., 1980).

CSF pterins in patients with defects of biopterin metabolism again reflect those in the periphery (Niederwieser et al., 1984; McInnes et al., 1984; Smith et al., 1985; Hyland et al., in press). In patients with

Table I Pterin species in CSF in patients with deficiency of phenylalanine hydroxylase or dihydropteridine reductase (DHPR)

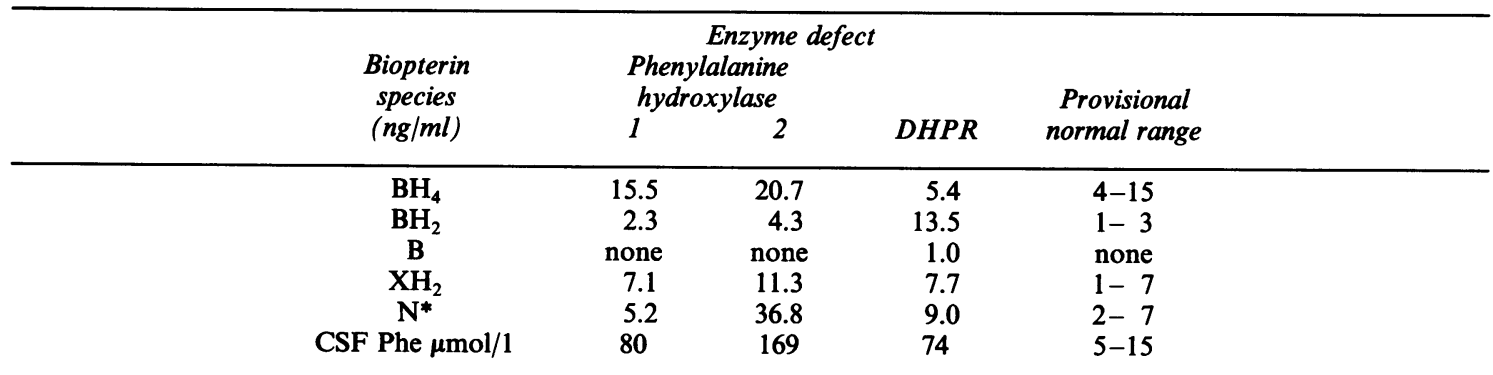

$\mathrm{N}=$ total neopterins, $\mathrm{BH}_{2}=7,8$,dihydrobiopterin, $\mathrm{BH}_{4}=5,6,7,8$,tetrahydrobiopterin, $\mathrm{XH}_{2}=$ dihydroxanthopterin,

$\mathrm{Phe}=$ plasma phenylalanine.

* Rises with viral illness to $50 \mathrm{ng} / \mathrm{ml}$ and above. 
DHPR deficiency CSF biopterins are elevated (Smith et al., 1985) and again most is $\mathrm{BH}_{2}$ (Hyland et al., in press). Recent direct measurement of $\mathrm{BH}_{4}$ concentrations in CSF suggests, however, that some $\mathrm{BH}_{4}$ is present (Table I) despite undetectable levels of DHPR in red cells (Leeming, personal communication). However, compared with CSF pterins in two patients with phenylalanine hydroxylase deficiency the proportion of total biopterin present as $\mathrm{BH}_{4}$ was low.

It has been suggested previously (Smith et al., 1985) that in patients with DHPR deficiency some turnover of $\mathrm{BH}_{4}$ occurs in the liver via the folate enzymes $5,10 \mathrm{CH}_{2} \mathrm{FH}_{4}$ reductase and DHFR, and that this may explain the relatively modest phenylalanine accumulation and fall of phenylalanine levels in response to administration of $\mathrm{BH}_{4}$. This hypothesis has yet to be confirmed but the CSF data support the idea that some turnover of $\mathrm{BH}_{4}$ continues (this time in the CNS) in the absence of DHPR activity, although perhaps outside amine producing cells since patients show severe amine deficiency.

\section{Neurotransmitter amines}

\section{Amine synthesis}

Synthesis of catecholamines and serotonin requires adequate intra-cellular concentrations of tyrosine and tryptophan, $\mathrm{BH}_{4}$ and the appropriate hydroxylase (Kaufman, 1981). The rate of amino acid transport across the blood-brain barrier is the main determinant of neuronal tyrosine and tryptophan concentrations (Pratt, 1981). The inter-play of these three factors is disrupted in all forms of hyperphenylalaninaemia with consequent disturbance of amine metabolism (Figures 4 and 5). Measurements of amines, and of amine metabolites such as homovanillic acid (HVA), the dopamine metabolite, and 5-hydroxyindoleacetic acid (5HIAA), the serotonin metabolite, have demonstrated a reduction in amine turnover in patients with phenylalanine hydroxylase deficiency (Lyman, 1961; McKean, 1972) and those with defective biopterin metabolism (Butler et al., 1978; McInnes et al., 1984; Niederwieser et al., 1984; Smith et al., 1985).

\section{Phenylalanine hydroxylase deficiency}

The central amine disturbance in patients with phenylalanine hydroxylase deficiency (Figures 4 and 5) is likely to be due to inhibition by phenylalanine of the transport of tyrosine and tryptophan from plasma into neurones (McKean, 1972; Pratt, 1981; Smith, 1985). Low concentrations of tyrosine and tryptophan, as well as of amines and their metabolites, are found in brain at post-mortem. The findings are consistent with the work of Wurtman \& Fernstrom

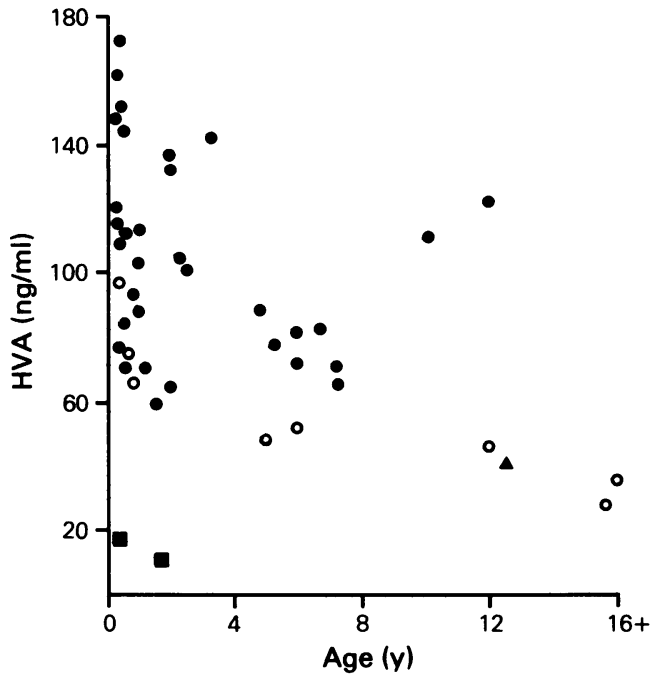

Figure 4 CSF homovanillic acid (HVA) concentrations versus age in children with phenylalanine hydroxylase deficiency $(O)$, arginase deficiency $(\Delta)$ and DHPR deficiency $(\square)$ compared with concentrations in children with neurological symptoms but without movement disorder (O). The youngest patient with phenylalanine hydroxylase deficiency was on well controlled diet (patient 1, Table I, plasma phenylalanine $300 \mu \mathrm{mol} / \mathrm{l}$ ) whereas the others were on a relaxed diet with blood phenylalanine concentrations between 900 and $1500 \mu \mathrm{mol} / 1$.

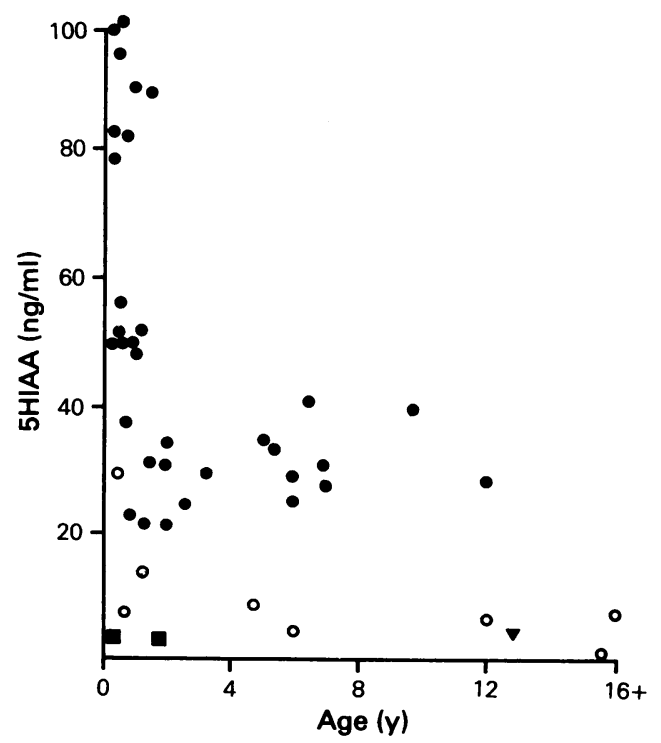

Figure 5 CSF 5-hydroxyindoleacetic acid (5HIAA) (see Figure 4). 
(1975) showing that the plasma amino acid pattern exerts physiological control over central amine metabolism.

Further evidence that amino acid competition is the cause of amine disturbance in phenylalanine hydroxylase deficiency comes from a recent study showing that a similar disturbance in CSF amine metabolites occurs (Figures 4 and 5) in arginase deficiency, a defect of the urea cycle causing hyperargininaemia but little or no hyperammonaemia (Hyland et al., 1985). There are no detectable pterin changes in arginase deficiency and, as in phenylalanine hydroxylase deficiency, amine disturbance is reduced by dietary treatment (Table III). In both disorders the effects on serotonin appear to be more severe than the effects on dopamine which is compatible with the finding that tryptophan hydroxylase is only $50 \%$ saturated by its substrate even at physiological concentrations of tryptophan (Kaufman, 1981). In contrast to the amino acid competition due to increased phenylalanine or arginine concentrations, hyperammonaemia damages the selectivity of the blood-brain barrier for amino acids and increases the rate of tryptophan transport into neurones from plasma. As a result, patients with defects of the urea cycle causing hyperammonaemia have raised serotonin metabolite levels in CSF (Bachman \& Colombo, 1983).

The neurological illness in patients with phenylalanine hydroxylase deficiency is dominated by mental retardation although other neurological abnormalities occur including myoclonic epilepsy, poor head control, hyperkinesis, increased limb tone, brisk tendon reflexes, ankle clonus and extensor plantar responses. Arginase deficiency is associated with similar symptoms. In older patients hyperactivity, fidgetyness, repetitive hand and facial movements and stereotyped

Table II Effects of diet therapy on CSF dopamine and serotonin metabolites; patients with deficiency of phenylalanine hydroxylase or arginase

\begin{tabular}{lccc}
\hline Enzyme defect & Diet & $\begin{array}{c}H V A \\
n g / m l\end{array}$ & $\begin{array}{c}5 H I A A \\
n g / m l\end{array}$ \\
\hline $\begin{array}{c}\text { Phenylalanine hydroxylase } \\
\text { Patient 1 }\end{array}$ & Off & 38 & 6 \\
& On & 44 & 16 \\
Patient 2 & Off & 27 & 0 \\
& On & 74 & 19 \\
Arginase & Off & 33 & 5 \\
& On & 60 & 16 \\
Normal range* & & $50-150$ & $20-120$
\end{tabular}

HVA = homovanillic acid, 5HIAA $=5$-hydroxyindoleacetic acid.

* Dependent on age, see Figures 4 and 5. behaviour are prominent, and Parkinsonian features have been noted (Paine, 1957). Even early treated children may, as the control of phenylalanine concentrations relaxes, develop subtle behaviour changes, intellectual deterioration, brisk jerks, ankle clonus and intention tremor (Smith, 1985).

It is possible that imbalance of central amine turnover contributes to the behaviour changes, dopamine deficiency to the Parkinsonian features and serotonin deficiency to the myoclonic epilepsy. In addition, the increased latency and decreased amplitude of visually evoked responses occurring in the presence of hyperphenylalaninaemia revert to normal when balanced amounts of L-dopa and 5hydroxytryptophan are given (McKean, 1972). Whether amine deficiency contributes to the more general neurological damage caused by hyperphenylalaninaemia is unknown.

\section{Tetrahydrobiopterin deficiency}

Patients with defective biopterin metabolism exhibit profound dopamine and serotonin deficiency (Figures 4 and 5) which is not corrected by control of phenylalanine accumulation. Such patients were first recognized (Smith et al., 1975; Kaufman et al., 1975; Rey et al., 1977; Bartholome et al., 1977) by the unusual and progressive character of the neurological illness and failure of the low phenylalanine diet to preven symptoms. These include extreme hypokinesis and trunk hypotonia, swallowing difficulty, drooling Parkinsonian facies, myoclonus, limb rigidity, oculogyric crises and recurrent hyperpyrexia. The movement disorder is much more prominent than in patients with phenylalanine hydroxylase deficiency and is consistent with the more profound alteration in dopamine metabolism. Serotonin deficiency could again contribute to the myoclonic epilepsy and explain the disturbance of temperature control.

Confirmation of the role of amine disturbance in the pathogenesis of symptoms comes from the dramatic improvement in some patients on treatment with $\mathrm{L}$ dopa, 5-hydroxytryptophan and carbidopa (Bartholome et al., 1977). Yet other factors undoubtedly make an important contribution to the neurological illness. Patients with defective biopterin synthesis have reduced birth weights (Smith \& Dhondt, 1985) suggesting an effect of the disease in utero. This may explain why amine replacement therapy and control of phenylalanine concentrations, even from infancy, may not prevent mental retardation (Endres et al., 1982). Patients with DHPR deficiency are of normal birth weight but develop severe folate deficiency (Butler et al., 1978), which is associated with progressive neurological deterioration (Harpey, 1983; Smith et al., 1985). 


\section{Relationship between biopterins, folates and amines}

\section{Links in biopterin and folate metabolism}

The metabolism of biopterins and folates appears to overlap at several points (Figures 2 and 6). DHFR reduces $\mathrm{BH}_{2}$ to $\mathrm{BH}_{4}$ in vitro (Nichol et al., 1983) and probably in vivo (Niederweiser et al., 1979). In vitro DHPR reduces quinonoid-dihydrofolates as well as q$\mathrm{BH}_{2}$ (Pollock \& Kaufman, 1978) and N5,N10-methylene tetrahydrofolate $\left(5,10 \mathrm{CH}_{2} \mathrm{THF}\right)$ reductase, which normally converts $5,10 \mathrm{CH}_{2} \mathrm{THF}$ to $5 \mathrm{CH}_{3} \mathrm{THF}$ reduces q-BH $\mathrm{BH}_{2}$ to $\mathrm{BH}_{4}$ (Matthews \& Kaufman, 1980). 5,6,7,8-tetrahydrofolate (THF) shows cofactor activity for phenylalanine hydroxylase in vitro (Kaufman, 1971). Findings in patients with defective biopterin synthesis, DHPR deficiency, $5,10 \mathrm{CH}_{2}$ THF re- ductase deficiencies, congenital folate malabsorption and methotrexate toxicity also point to important links between folate and biopterin metabolism.

\section{Hydroxylase cofactor activity and folate}

Administration of folic acid to a patient with defective biopterin synthesis led to lowering of plasma phenylalanine and a rise in plasma tyrosine and serotonin (Hase et al., 1982). Folate antagonists, such as amethopterin, block the conversion of phenylalanine to tyrosine in vivo (Goodfriend \& Kaufman, 1961) as well as inhibiting DHFR and displacing folate in polyglutamates. The data suggest that folates may have hydroxylase cofactor activity in vivo as well as in vitro which might explain the near normal 'hydroxylase cofactor activity' in liver from a patient with

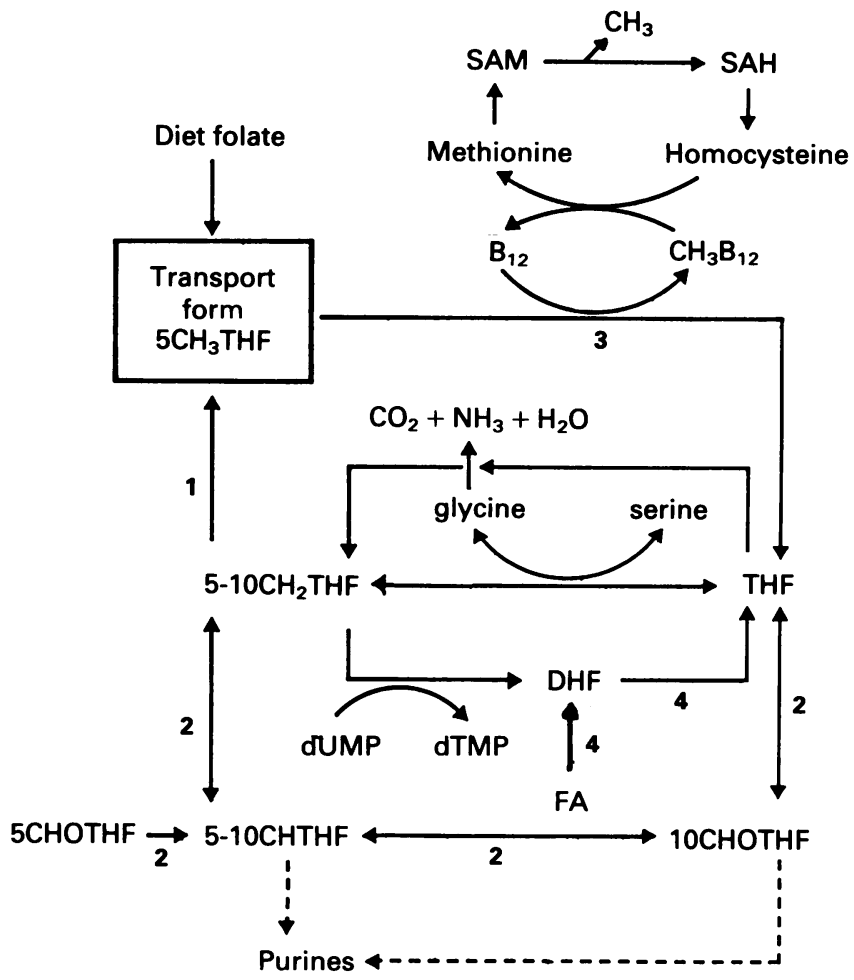

Figure 6 Simplified outline of folate turnover to illustrate conversion of 5,10-methylenetetrahydrofolate $\left(5,10 \mathrm{CH}_{2} \mathrm{THF}\right)$ to $\mathrm{N} 5$-methyltetrahydrofolate $\left(5 \mathrm{CH}_{3} \mathrm{THF}\right)$, and transfer of methyl groups $\left(-\mathrm{CH}_{3}\right)$ to homocysteine to form methionine. Formamanino-group transfer is omitted. THF $=5,6,7,8$-tetrahydrofolate (tetrahydropteroylglutamic acid); $5,10 \mathrm{CH}_{2} \mathrm{THF}=5,10$-methenylTHF; $10 \mathrm{CHOTHF}=10$-formylTHF; $5 \mathrm{CHOTHF}=5$-formylTHF (folinic acid); DHF = 7,8-dihydrofolate; FA = folic acid (pteroylglutamic acid); SAM = $s$-adenosylmethionine; $\mathrm{SAH}=s$-adenosylhomocysteine; $\mathrm{dUMP}=$ deoxyuridine monophosphate; $\mathrm{dTMP}=$ deoxythymidine monophosphate. Enzymes: $1=5,10 \mathrm{CH}_{2}$ THF reductase, $2=$ formyl,methenyl,methyleneTHF synthetase, $3=5 \mathrm{CH}_{3} \mathrm{THF}$; homocysteine methyltransferase, $4=$ DHF reductase. 
defective biopterin synthesis (Bartholome et al., 1977) despite low biological biopterin activity (Leeming \& Smith, 1979).

\section{Folate antagonists}

It has been suggested that the effect of amethopterin on phenylalanine metabolism in vivo is due to inhibition of DHPR activity (Goodfriend \& Kaufman, 1961) but there is no confirmation of this. Indeed, children receiving amethopterin for treatment of leukaemia do not show decreased central amine turnover but rather increased turnover of both biopterins and amines (Leeming et al., 1976c; Pinkerton et al., 1985). This observation is compatible with the effect of amethopterin on biopterin metabolism in vitro where the drug blocks conversion of exogenous $\mathrm{BH}_{2}$ to $\mathrm{BH}_{4}$ (due to inhibition of DHFR) but increases de novo $\mathrm{BH}_{4}$ synthesis (Nichol et al., 1983). The data suggest that folate may be a physiological inhibitor of biopterin synthesis and indeed folates reduce the activity of GTP cyclohydrolase in vitro (Kapatos \& Kaufman, 1983).

\section{Folate disturbance in DHPR deficiency}

Patients with DHPR deficiency develop low concentrations of total folate in serum, red cells and CSF (Butler et al., 1978; Tada et al., 1980; Harpey, 1983; Smith et al., 1985). As yet there are no published reports of investigations of folate metabolism in patients with defective biopterin synthesis. Neurological deterioration has been clearly linked to the folate disturbance in patients with DHPR de- ficiency (Table III) (Harpey, 1983; Smith et al., 1985) and development of folate deficiency may be accompanied by CT scan changes showing calcification in the lentiform nucleus extending into the periphery with attenuation in the white matter suggestive of demyelination (Tada et al., 1980; Smith et al., 1985). This same appearance has been described in patients with congenital folate malabsorption and in children with leukaemia who have received amethopterin (Smith et al., 1985; Corbeel et al., 1985). Examination of the brain in one patient (Tada et al., 1980) showed diffuse demyelinating lesions with micro-calcification localized around small blood vessels, an appearance also reported in a patient with $5,10 \mathrm{CH}_{2} \mathrm{THF}$ reductase deficiency (Wong et al., 1977).

Despite low levels of folate in red cells and serum, patients with DHPR deficiency show no haematological or other peripheral signs of folate lack and in this they resemble patients with $5,10 \mathrm{CH}_{2}$ THF reductase deficiency (Wong et al., 1977; Niederwieser, 1979). The latter disorder causes neurological symptoms which include progressive pyramidal, spino-cerebellar and dorsal column degeneration accompanied by developmental regression and Parkinsonism. A diagnosis of subacute combined degeneration of the cord with severe cerebral involvement due to folate lack has been confirmed at post-mortem in one patient (Clayton et al., 1985). Following the development of symptoms of cord damage a clinical diagnosis of subacute combined degeneration was also made in aq patient with DHPR deficiency (Smith et al., 1985).

$5,10 \mathrm{CH}_{2} \mathrm{THF}$ reductase is required for normal turnover in vivo of $5 \mathrm{CH}_{3}$ THF (Figure 6). This is the

Table III Folate and amine disturbance in a patient with dihydropteridine reductase deficiency. Total folate by Lactobacillus caseii assay

\begin{tabular}{|c|c|c|c|c|c|c|}
\hline & $\begin{array}{l}\text { Age in } \\
\text { months }\end{array}$ & $\begin{array}{c}\text { Red cell } \\
\text { folate } \\
(n g / m l)\end{array}$ & $\begin{array}{l}\text { Serum } \\
\text { folate } \\
(\mathrm{ng} / \mathrm{ml})\end{array}$ & $\begin{array}{l}\text { Folate } \\
(n g / m l)\end{array}$ & $\begin{array}{c}C S F \\
H V A\end{array}$ & l) $5 H I A A$ \\
\hline Diagnosis DHPR deficiency - hypoton & nia hypkin & & & & & \\
\hline Diet only & 3 & 1210 & 34 & $36^{*}$ & 17 & 5 \\
\hline $\begin{array}{l}\text { Good progress - normal development } \\
\text { Diet + L-dopa, } 50 \mathrm{Htrypt}\end{array}$ & 9 & 920 & 26 & $25^{*}$ & 102 & 38 \\
\hline $\begin{array}{l}\text { Deterioration begins } \\
\text { BH4 + L-dopa, 50Htrypt }\end{array}$ & 29 & not done & not done & $6^{*}$ & 34 & 14 \\
\hline $\begin{array}{l}\text { Progressive neurological disease } \\
\text { L-dopa } 50 \mathrm{Htrypt}\end{array}$ & 33 & 61 & 3 & 4 & 116 & 60 \\
\hline $\begin{array}{l}\text { Diagnosis of folate deficiency - given } \\
\text { Folic acid } 2.5 \mathrm{mg} / \mathrm{kg} \text { for } 10 \text { days }\end{array}$ & $\begin{array}{l}\text { folic acid } \\
\quad 33\end{array}$ & 134 & 13 & 3 & 20 & 12 \\
\hline $\begin{array}{l}\text { Given folinic acid - improved }++ \text { bu } \\
\text { Folinic acid } 3 \mathrm{mg} / \mathrm{d} \text { for } 4 \text { months }\end{array}$ & $\begin{array}{l}\text { cord les } \\
37\end{array}$ & $\begin{array}{l}\text { persists } \\
>1000\end{array}$ & 36 & 26 & 109 & 28 \\
\hline
\end{tabular}

Normal values: red cell $150-300 \mathrm{ng} / \mathrm{ml}$, serum $10-15 \mathrm{ng} / \mathrm{ml}$, CSF $18-50 \mathrm{ng} / \mathrm{ml}$.

* Measurements made at 33 months of age on stored CSF. 
form of folate present in plasma and it is transported preferentially across the blood-brain barrier (Levitt $e t$ al., 1971). $5 \mathrm{CH}_{3}$ THF is also donor of the methyl group for methyl-cobalamin, the derivative of vitamin B12 (Figure 6) required for conversion of homocysteine to methionine (Nixon \& Bertino, 1970; Scott et al., 1983). It is not surprising therefore that deficiency of $5,10 \mathrm{CH}_{2} \mathrm{FH} 4$ reductase should cause the same lesions as vitamin $\mathrm{B} 12$ deficiency.

To try and explain the folate disturbance in DHPR deficiency it has been proposed that the dihydropterins which accumulate in this disease interfere with folate metabolism, perhaps by competitively inhibiting 5,10CH $\mathrm{CH}_{2}$ THF reductase and DHFR (Smith et al., 1985). The beneficial effects of 5-formyltetrahydrofolate (folinic acid) in patients with deficiency of DHPR (Harpey, 1983; Smith et al., 1985), or $5,10 \mathrm{CH}_{2}$ THF reductase (Harpey et al., 1981), could then be attributed to an increase in the concentrations of substrate for the folate reductases and increased synthesis of THF (Figure 6).

Folic acid exacerbates symptoms in patients with DHPR deficiency (Harpey, 1983; Smith et al., 1985), and in some patients with deficiency of $5,10 \mathrm{CH}_{2} \mathrm{THF}$ reductase (Clayton et al., 1985). The harmful effect of folic acid on the neurological disease in $\mathbf{B}_{12}$ deficient patients is well known. Administration of folic acid causes a rise in plasma concentrations of non-methyl folates (Ratanasthien et al., 1977), and 10 days' folic acid therapy in a patient with DHPR deficiency failed to raise CSF folate levels (Table III). It is suggested that folic acid reduced transport of $5 \mathrm{CH}_{3} \mathrm{THF}$ across the blood-brain barrier (Levitt et al., 1971) and

\section{References}

BACHMAN, C. \& COLOMBO, J.P. (1983). Increased tryptophan uptake into brain in hyperammonaemia. Life Sciences, 33, 2417.

BARTHOLOME, K., BYRD, D.J., KAUFMAN, S. \& MILSTIEN, S. (1977). Atypical phenylketonuria with normal phenylalanine hydroxylase and dihydropteridine reductase activity in vitro. Pediatrics, 47, 736.

BOTEZ, M.I., YOUNG, S.N., BACHEVALIER, J. \& GAUTHIER, S. (1979). Folate deficiency and decreased brain 5-hydroxytryptamine synthesis in man and rat. Nature, 278, 182.

BUTLER, I.J., KOSLOW, S.H., KRUMHOLZ, A., HOLTZMAN, N.A. \& KAUFMAN, S. (1978). A disorder of biogenic amines in dihydropteridine reductase deficiency. Annals of Neurology, 3, 224.

CLAYTON, P.T., SMITH, I., HARDING, B., HYLAND, K., LEONARD, J.V. \& LEEMING, R.J. (1985). Subacute combined degeneration of the cord, dementia and parkinsonism due to an inborn error of folate metabolism. Journal of Neurology, Neurosurgery and Psychiatry, in press.

CORBEEL, L., VAN DEN BERGHE, G., JAEKEN, J., VAN TORNOUT, J. \& EECKELS, R. (1985). Congenital folate malabsorption. European Journal of Pediatrics, 143, 284. competed with dihydrofolate for DHFR thus exacerbating neuronal deficiency of tetrahydrofolates.

Finally, patients with $5,10 \mathrm{CH}_{2}$ THF reductase deficiency exhibit not only Parkinsonism but also severely reduced CSF concentrations of HVA, 5HIAA, biopterins and neopterins (Harpey et al., 1981; Clayton et al., 1985) and patients with DHPR deficiency receiving amine replacement therapy also show exacerbation of amine deficiency when folate deficiency supervenes (Harpey, 1983; Smith et al., 1985). Folic acid administration was accompanied by increased clinical and biochemical evidence of amine disturbance in a patient with DHPR deficiency (Table III) (Smith et al., 1985) and another with $5,10 \mathrm{CH}_{2} \mathrm{THF}$ reductase deficiency (Clayton et al., 1985). Dietary folate deficiency, or loading with folic acid, are associated with reduced amine metabolites in CSF in the rat and in humans (Botez et al., 1979).

To explain the amine disturbance it is suggested that methyl-folate deficiency inhibits release of amine neurotransmitters at nerve endings, although no information is available to confirm this. There seems little doubt, however, that the metabolism of folates, biopterins and amines is closely linked, although the mechanisms and functions remain to be elucidated.

\section{Acknowledgements}

Dr K. Hyland is in receipt of a Research Fellowship from the McAlpine Foundation. We also wish to thank the Medical Research Council and Action Research for the Crippled Child for their financial support.

COUGHLAN, M.P. (1983). The molybdenum cofactor in human biology. Journal of Inherited Metabolic Disease, 6 (Suppl 1), 70.

CURTIUS, H-Ch., HEINTEL, D., GHISLA, S., KUSTER, T., LEIMBACHER, W. \& NIEDERWIESER, A. (1985). Biosynthesis of tetrahydrobiopterin in man. Journal of Inherited Metabolic Disease, 8 (Suppl 1), 20.

DHONDT, J-L., ARDOUIN, P., HAYTE, J.M. \& FARRIAUX, J.P. (1981). Developmental aspects of pteridine metabolism and relationship with phenylalanine metabolism. Clinica Chimica Acta, 116, 143.

ENDRES, W., NIEDERWIESER, A., CURTIUS, H-Ch., WANG, M., OHRT, B. \& SCHAUB, J. (1982). Atypical phenylketonuria due to biopterin deficiency. Early treatment with tetrahydrobiopterin and neurotransmitter precursors, trials of tetrahydrobiopterin monotherapy. Helvetica Paediatrica Acta, 37, 489.

GOODFRIEND, T.L. \& KAUFMAN, S. (1961). Phenylalanine metabolism and folic acid antagonists. Journal of Clinical Investigation, 40, 1743.

HARPEY, J-P. (1983). Les defauts de synthese des biopterines: les deficits complete (reductase et synthetase). Archives 
Francaises Pediatrie, 40 (suppl 1), 231.

HARPEY, J-P., ROSENBLATT, D.S., COOPER, B.A., LE MOEL, G., ROY, C. \& LAFOURCADE, J. (1981). Homocystinuria caused by 5,10 -methylenetetrahydrofolate reductase deficiency: A case in an infant responding to methionine, folinic acid, pyridoxine and vitamin B12 therapy. Journal of Pediatrics, 98, 275.

HASE, Y., SHINTAKU, H., TURUHARA, T., OURA, T., KOBASHI, M. \& IWAI, I. (1982). A case of tetrahydrobiopterin deficiency due to defective synthesis of dihydrobiopterin. Journal of Inherited Metabolic Disease, 5, 81.

HUBER, Ch., FUCHS, D. \& HAUSEN, A. (1983). Pteridines as a new marker to detect human T-cells activated by allogenic or modified-self major histocompatability complex (MHC) determinants. Journal of Immunology, 160, 1047.

HYLAND, K. (1985). The estimation of tetrahydro-, dihydro-, and fully oxidized pterins by high performance liquid chromatography using sequential electrochemical fluorimetric detection. Journal of Chromatography, 343, 35.

HYLAND, K., SMITH, I., CLAYTON, P.T. \& LEONARD, J.V. (1985a). Impaired neurotransmitter amine metabolism in arginase deficiency. Journal of Neurology, Neurosurgery and Psychiatry, 48, 1188.

HYLAND, K., SMITH, I., HOWELLS, D.W., CLAYTON, P.T. \& LEONARD, J.V. (1985b). The determination of pterins, biogenic amine metabolites and aromatic amino acids in cerebrospinal fluid using isocratic reverse phase liquid chromatography with in series dual cell coulometric electrochemical and fluorescence detection: use in a study of inborn errors of dihydropteridine reductase and 5.10 methylenetetrahydrofolate reductase deficiency. In Biochemical and Clinical Aspects of Pteridines, Vol. 4. Wachter, H., Curtius H-Ch. \& Pfleiderer, W. (eds), p. 85. Walter de Gruyter: Berlin.

KAPATOS, G. \& KAUFMAN, S. (1983). Inhibition of pterin biosynthesis in the adrenergic neuroblastoma N1E115 by tetrahydrobiopterin and folate. In Chemistry and Biology of Pteridines. J.A. Blair (ed). pp. 171-5. Walter de Gruyter: Berlin.

KAUFMAN, S. (1971). The phenylalanine hydroxylating system from mammalian liver. Advances in Enzymology, 352, 45.

KAUFMAN, S., HOLTZMAN, N.A., MILSTIEN, S., BUTLER, I.J. \& KRUMHOLZ, A. (1975). Hyperphenylalaninaemia due to a deficiency of dihydropteridine reductase. New England Journal of Medicine, 299, 673.

KAUFMAN, S. (1976). Phenylketonuria: biochemical mechanisms. In Advances in Neurochemistry, Vol. 2, Agranoff, B.W. \& Aprison, M.H. (eds). pp. 1-132. Plenum Press: New York.

KAUFMAN, S. (1981). Regulatory properties of pterin dependent hydroxylases: variations on a theme. In Function and Regulation of Monoamine Enzymes, Usdin, E., Weiner, N. \& Youdim, M.B.H. (eds). pp. 165-73. Macmillan Press: London.

KAUFMAN, S. (1985). Hyperphenylalaninaemia caused by defects in biopterin metabolism. Journal of Inherited Metabolic Disease, 8 (Suppl 1), 20.

LEEMING, R.J., BLAIR, J.A., GREEN, A. \& RAINE, D.N. (1976a). Biopterin derivatives in normal and phenylketonuric patients after oral loads of L-phenylalanine, L-tyrosine and L-tryptophan. Archives of Disease in Childhood, 51,
771.

LEEMING, R.J., BLAIR, J.A. \& REY, F. (1976b). Biopterin derivatives in atypical phenylketonuria. Lancet, i, 99.

LEEMING, R.J., BLAIR, J.A., MELIKIAN, V. \& O'GORMAN, D.J. (1976c). Biopterin derivatives in human body fluids and tissues. Journal of Clinical Pathology, 29, 444.

LEEMING, R.J. \& SMITH, I. (1979). Biopterin deficiency in PKU. New England Journal of Medicine, 300, 198.

LEEMING, R.J., BARFORD, P.A., BLAIR, J.A. \& SMITH, I. (1984). Blood spots on Guthrie cards can be used for inherited tetrahydrobiopterin deficiency screening in hyperphenylalaninaemic infants. Archives of Diseases of Childhood, 59, 58.

LEVITT, M., NIXON, P.F., PINCUS, J.H. \& BERTINO, J.R. (1971). Transport characteristics of folates in cerebrospinal fluid; a study utilizing doubly labelled 5-methyltetrahydrofolate and 5-formyltetrahydrofolate. Journal of Clinical Investigation, 50, 1301.

LYMAN, F.L. (1961). In Phenylketonuria. Charles C. Thomas. Springfield.

MCINNES, R., KAUFMAN,, S., WARSH, J.J., VAN LOON, G., MILSTIEN, S., KAPATOS, G., SOLDIN, S., WALSH, P., MACGREGOR, D. \& HANLEY, W.B. (1984). Treatment with L-dopa and 5-hydroxytryptophan compared with therapy with tetrahydrobiopterin. Journal of Clinical Investigation, 73, 458.

MCKEAN, C.M. (1972). The effects of high phenylalanine concentrations on the serotonin and catecholamine metabolism in the human brain. Brain Research, 47, 469.

MATTHEWS, R.G. \& KAUFMAN, S. (1980). Characterization of the dihydropterin reductase activity of pig liver methylene tetrahydrofolate reductase. Journal of Biological Chemistry, 255, 6014.

MILSTIEN, S., KAUFMAN, S. \& SUMNER, G.K. (1980). Hyperphenylalaninaemia due to dihydropteridine reductase deficiency: diagnosis by measurement of oxidized and reduced pterins in urine. Pediatrics, 65, 806.

MILSTIEN, S. \& KAUFMAN, S. (1983). The regulation of biopterin biosynthesis in the rat. In Chemistry and Biology of Pteridines, Blair, J.A. (ed). pp. 753-7. Walter de Gruyter: Berlin.

NICHOL, C.A., LEE, C.L., EDELSTEIN, M.P., CHAO, J.Y. \& DUCH, D.S. (1983). Biosynthesis of tetrahydrobiopterin by de novo and salvage pathways in adrenal medulla extracts, mammalian cell cultures and rat brain in vivo. Proceedings of the National Academy of Sciences (USA), 80, 1546.

NIEDERWIESER, A. (1979). Inborn errors of pterin metabolism. In Folic Acid in Neurology, Psychiatry and Internal Medicine, Botez, M.I. \& Reynolds, E.H. (eds). pp. 349-84. Raven Press: New York.

NIEDERWIESER, A., CURTIUS, H-Ch., BETTONI, O., BIERI, J., SCHIRCKS, B., VISCONTINI, M. \& SCHAUB, J. (1979). Atypical phenylketonuria caused by 7,8-dihydrobiopterin synthetase deficiency. Lancet, i, 131.

NIEDERWIESER, A., CURTIUS, H-Ch., GITZELMANN, R., OTTEN, A., BAERLOCHER, K., BLEHOVA, B., BERLOW, S., GROBE, H., REY, F., SCHAUB, J., SCHEIBENREITER, S., SCHMIDT, H. \& VISCONTINI, M. (1980). Excretion of pterins in phenylketonuria and phenyketonuria variants. Helvetica Paediatrica Acta, 35, 335.

NIEDERWIESER, A., BLAU, N., WANG, M., JOLLER, P., ATARES, M. \& CARDESIA-GARCIA, J. (1984). GTP cyclohydrolase I deficiency, a new enzyme defect causing 
hyperphenylalaninaemia with neopterin, biopterin, dopamine and serotonin deficiencies and muscular hypotonia. European Journal of Pediatrics, 141, 208.

NIEDERWIESER, A., PONZONE, A. \& CURTIUS, H-Ch. (1985). Differential diagnosis of tetrahydrobiopterin deficiency. Journal of Inherited Metabolic Disease, 8 (Suppl 1), 34.

NIXON, J.C., LEE, C.L., MILSTIEN, S., KAUFMAN, S. \& BARTHOLOME, K. (1980). Neopterin and biopterin levels in patients with atypical forms of phenylketonuria. Journal of Neurochemistry, 35, 898.

NIXON, P.F. \& BERTINO, J.R. (1970). Inter-relationship of vitamin B12 and folate in man. American Journal of Medicine, 48, 555.

PAINE, R.S. (1957). The variability in manifestations of untreated patients with phenylketonuria (phenylpyruvic aciduria). Pediatrics, 20, 290.

PFLEIDERER, W. (1982). Properties of naturally-occurring pteridines. In Biochemical and Clinical Aspects of Pteridines, Vol. 1, Wachter, H., Curtius, H-Ch. \& Pfleiderer, W. (eds). pp. 3-26. Walter de Gruyter: Berlin.

PINKERTON, C.R., SMITH, I., LEEMING, R.J., SARNA, G., HYLAND, K., CURZON, G. \& CHESSELS, J.M. (1986). Methotrexate therapy is not associated with neurotransmitter amine deficiency. Journal of Pediatrics. (in press).

POLLOCK, R.J. \& KAUFMAN, S. (1978). Dihydropteridine reductase may function in tetrahydrofolate metabolism. Journal of Neurochemistry, 31, 115.

PRATT, O.E. (1981). The needs of the brain for amino acids and how they are transported across the blood-brain barrier. In Transport and Inherited Disease, Belton, N.R. \& Toothill, C. (eds). pp. 87-122. MTP Press: Lancaster.

REY, F., HARPEY, J.P., LEEMING, R.J., BLAIR, J.A., AICARDI, J. \& REY, J. (1977). Les hyperphenylalaninemies avec activite normal de la phenylalanine hydroxylase. Le deficit en tetrahydrobiopterine et le deficit en reductase. Archives Francaises de Pediatrie, 37 (suppl 1), 109.

REY, F., SAUDUBRAY, J.M., LEEMING, R.J., NIEDERWIESER, A., CURTIUS, H-Ch. \& REY, J. (1983). Les deficits partiels en tetrahydrobiopterine. Archives Francaises de Pediatrie, 40 (suppl 1), 237.

RATANASTHIEN, K., BLAIR, J.A., LEEMING, R.J., COOKE, W.T. \& MELIKIAN, V. (1977). Serum folates in man. Journal of Clinical Pathology, 30, 438.

SCOTT, J.M., DINN, J.J., WILSON, P. \& WEIR, D.G. (1981). Pathogenesis of subacute combined degeneration: a result of methyl group deficiency. Lancet, ii, 334.

SMITH, I. (1985). The hyperphenylalaninaemias. In Genetic and Metabolic Disease, Lloyd, J.K. \& Scriver, C.R. (eds). pp. 166-209. Butterworth's International Medical Reviews. Pediatrics 5. Butterworths: London.

SMITH, I., CLAYTON, B.E. \& WOLFF, O.H. (1975). A new variant of phenylketonuria with progressive neurological illness unresponsive to phenylalanine restriction. Lancet, $\mathbf{i}$, 1108.

SMITH, I., HYLAND, K., KENDALL, B. \& LEEMING, R.J. (1985). Clinical role of pteridine therapy in tetrahydrobiopterin deficiency. Journal of Inherited Metabolic Disease, 8 (Suppl 1), 39.

SMITH, I. \& DHONDT, J-L. (1985). Birthweight in patients with defective biopterin metabolism. Lancet, i, 818.

TADA, K., NARISAWA, K., ARAI, N., OGASAWARA, Y. \& ISHIZAWA, S. (1980). A sibling case of hyperphenylalaninaemia due to deficiency of dihydropteridine reductase. Biochemical and pathological findings. Tohoku Journal of Experimental Medicine, 132, 123.

TIETZ, A., LINDBERG, M. \& KENNEDY, E.P. (1964). A new pteridine-requiring enzyme system for oxidation of glyceryl ethers. The Journal of Biochemical Chemistry, 239, 4081.

WONG, P.W.K., JUSTICE, HRUBY, M., WEISS, E.B. \& DIAMOND, E. (1977). Folic acid nonresponsive homocystinuria due to methylene tetrahydrofolate reductase deficiency. Pediatrics, 59, 749.

WURTMAN, R.J. \& FERNSTROM, J.D. (1975). Control of brain monoamine synthesis by diet and plasma amino acids. American Journal of Clinical Nutrition, 28, 638. 